\title{
The Effectively of Papaya Consumption (Carica papaya Linn.), Vitamin C, and Fe Tablets in Improving Hemoglobin Levels for Adolescent Girls with Anemia in Polytechnic of Health-Ministry of Health, Aceh
}

\author{
Cut Nurhasanah ${ }^{1 *}$, Yushida Yushida ${ }^{2}$, Nisrina Hanum ${ }^{2}$ \\ ${ }^{1}$ Department of Midwifery, Polytechnic of Health-Ministry of Health, Aceh, Indonesia; ${ }^{2}$ Department of Midwifery, Ministry of \\ Health Polytechnic of Meulaboh, Aceh, Indonesia
}

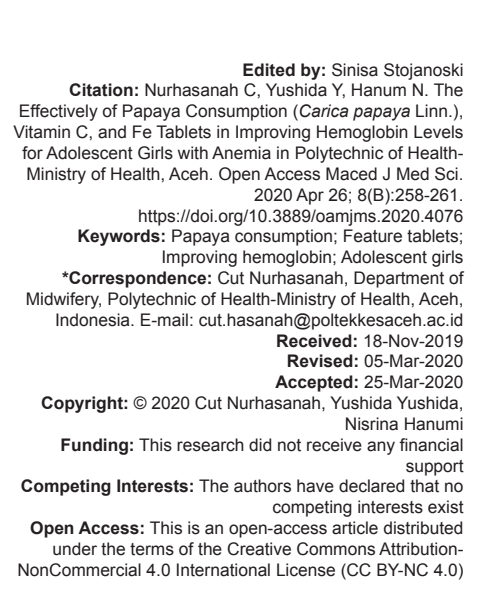

\section{Introduction}

Anemia is a nutritional problem that is experienced by many people around the world. Anemia is a global public health problem affecting 305 million school children (SC) worldwide [1]. The prevalence of anemia in the world of reproductive age (15-49 years) is $29.4 \%$, while in Indonesia, it is $22 \%$ [2]. Nationally, with anemia patients aged $15-24$ years by $18.4 \%$. Based on sex, it was found that the prevalence of anemia in women was higher $(22.8 \%)$ than in men $(20.6 \%)$. The 2012 Household Health Survey (SKRT) stated that the prevalence of anemia in adolescent girls aged $10-18$ years was $57.1 \%$ and those aged $19-45$ years were $39.5 \%$ [3].

Anemia is a condition where the level of hemoglobin or red blood cells in the body is below normal so that if left unchecked, it can cause health problems for those who suffer from it [4]. Anemia is measured by hemoglobin levels, i.e., for women in groups fertile age (15-49 years) with hemoglobin levels $<12.0 \mathrm{~g} / \mathrm{dL}$, whereas men aged $\geq 15$ years with hemoglobin levels $<13.0 \mathrm{~g} / \mathrm{dL}$ [3]. The contributing factors of anemia are low socioeconomic status, the onset of menarche, small family size, and vegetarian [5]. One problem that is often experienced by adolescents is anemia. It can affect the level of productivity which causes a decrease in physical activity and academic and non-academic achievement. Anemia in adolescents can cause growth disorders, easily tired, susceptible to infection, and reduced physical ability [6], [7]. Normally, anemia is significantly related to women who experience regular menstruation compared to irregular ones [8], [9], [10]. In general, the high prevalence of anemia is caused by several factors, namely, low intake of iron and other nutrients such as Vitamin A, Vitamin C, folate, riboflavin, and B12. Giving blood added tablets are one of the efforts in preventing and controlling anemia. Consumption of papaya fruit can be an alternative to prevent anemia because it contains Vitamin C, namely, Vitamin C (78 $\mathrm{mg} / 100 \mathrm{~g})$ and folate $(38 \mu \mathrm{g} / 100 \mathrm{~g})$ [10]. The content of Vitamin $C$ in papaya is thought to meet the needs of Vitamin $\mathrm{C}$ and folate for adolescents. The prevalence 
of adolescents who get blood-supplemented tablets in Indonesia is $10.3 \%$ and adolescents who get blood-added tablets in Aceh are $24.7 \%$. This study aimed to analyze the consumption of Papaya (Carica papaya Linn.) Vitamin $\mathrm{C}$ and $\mathrm{Fe}$ tablet can increase hemoglobin levels in young girls who experience anemia.

\section{Methods}

The design of this study is a quasi-experiment. The design used was a non-randomized pretest-posttest control group design. This research was successfully conducted at the Department of Midwifery at the Polytechnic of the Ministry of Health in Aceh on January 23, 2019 to April 12, 2019. The population in this study was all adolescent girls who were anemic in Polytechnic of HealthMinistry of Health, Aceh. The sample was chosen about 45 people using a purposive sampling technique. The basis of sample selection is due to experimental research. They were divided into three groups for 15 correspondents in each group that was all young women who were suffered from anemia. The treatment went on and the first group was given papaya and Fe treatment then the second group was given Vitamin $\mathrm{C}$ and Fe treatment, and the third group was given Fe treatment. The treatment is given for 12 weeks. After data were collected, then analyzed using univariate analysis and bivariable analysis to test paired t-test and one-way ANOVA.

\section{Results}

\section{Characteristics of respondents}

Respondent characteristics are inherent characteristics in individuals; in this study includes the age of Midwifery Department Students and the age of Menarche.

Table 1 shows that in the papaya and Fe group the majority of adolescent girls were 18-19 years old $(60 \%)$, the majority of Vitamin C and Fe group were 21-22 years of age (93.3\%), and the majority of the $\mathrm{Fe}$ group were $21-22$ years $(66.7 \%)$. In all three groups, the menarche was detected in the age group 13-14 years (53.3\%), (46.6\%), and (60\%), respectively.

\section{Univariate analysis}

The univariate analysis aims to explain or describe the characteristics of each research variable. Univariate analysis was conducted to see changes in hemoglobin levels before and after treatment.
Table 1: Distribution of student age and menarche age student of midwifery department

\begin{tabular}{llll}
\hline Age respondent & Group & & \\
\cline { 2 - 4 } & Papaya + Fe & Vitamin C + Fe & $\mathrm{Fe}$ \\
\hline $17-18$ & 9 & 0 & 1 \\
$19-20$ & 4 & 0 & 4 \\
$21-22$ & 2 & 14 & 10 \\
$23-24$ & 0 & 1 & 0 \\
& 15 & 15 & 15 \\
\hline Age menarche. & Papaya + Fe & Vitamin C + Fe & $\mathrm{Fe}$ \\
\hline $11-12$ & 5 & 4 & 4 \\
$13-14$ & 8 & 7 & 9 \\
$15-16$ & 2 & 4 & 2 \\
& 15 & 15 & 15 \\
\hline
\end{tabular}

The average hemoglobin level in the papaya and $\mathrm{Fe}$ group was $10.02 \% \mathrm{~g}$, the Vitamin $\mathrm{C}$ and $\mathrm{Fe}$ group was $10.74 \% \mathrm{~g}$, and the $\mathrm{Fe}$ group was $10.54 \%$ (Table 2).

Table 2: Hemoglobin levels before intervention

\begin{tabular}{lllll}
\hline Groups & Means & Deviation standard & Min. & Max. \\
\hline Papaya and Fe & 10.2 & 1.11 & 7.20 & 11.50 \\
Vitamin C and Fe & 10.74 & 0.76 & 9.50 & 11.90 \\
$\mathrm{Fe}$ & 10.54 & 1.08 & 9.50 & 11.80 \\
\hline
\end{tabular}

The average hemoglobin level in the papaya and $\mathrm{Fe}$ groups was $12.02 \% \mathrm{~g}$, the treatment Group II was $12.08 \% \mathrm{~g}$, and the control group was $11.40 \%$ (Table 3).

Table 3: Hemoglobin levels after intervention

\begin{tabular}{lllll}
\hline Groups & Means & Deviation standard & Min. & Max. \\
\hline Papaya and Fe & 12.02 & 0.79 & 10.50 & 13.50 \\
Vitamin C and Fe & 12.08 & 1.27 & 8.60 & 13.50 \\
Fe & 11.40 & 1.08 & 9.60 & 13.10 \\
\hline \multicolumn{2}{c}{ The } & & & \\
& average & hemoglobin level in the
\end{tabular}
papaya group and $\mathrm{Fe} 2.00 \% \mathrm{~g}$, the Vitamin $\mathrm{C}$ and $\mathrm{Fe}$ group $1.34 \% \mathrm{~g}$, and the Fe group $0.85 \% \mathrm{~g}$ (Table 4 ).

Table 4: Hemoglobin levels before and after treatment

\begin{tabular}{llll}
\hline Treatment group & Before Mean \pm SD & After Mean \pm SD & $\Delta$ Mean \pm SD \\
\hline Papaya and Fe & $10.02 \pm 1.11$ & $12.02 \pm 0.79$ & $2.00 \pm 0.94$ \\
Vitamin C and Fe & $10.74 \pm 0.76$ & $12.08 \pm 1.27$ & $1.34 \pm 1.27$ \\
Fe & $10.54 \pm 1.08$ & $11.40 \pm 1.08$ & $0.85 \pm 1.17$ \\
\hline
\end{tabular}

One-way ANOVA test results showed a significant difference in changes in hemoglobin levels $(p<0.05)$ (Table 5 and Figure 1).

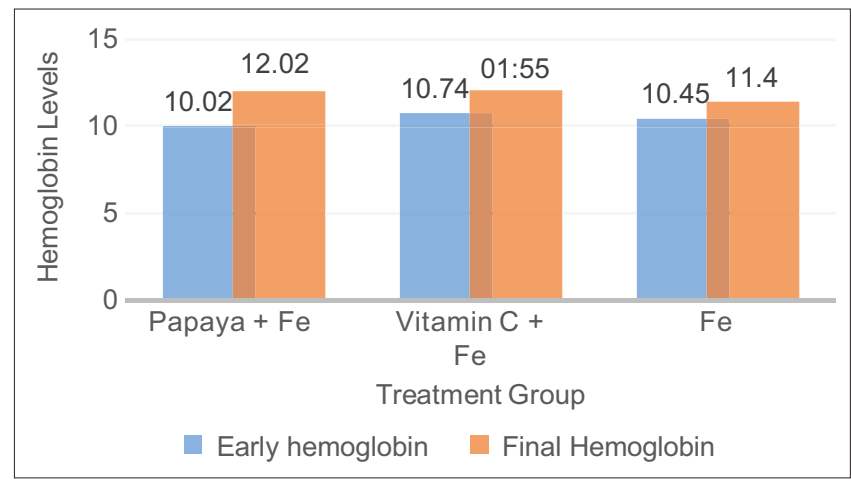

Figure 1: Changes in hemoglobin levels

\section{Bivariate analysis}

Bivariate analysis was performed to see the relationship between variables in the hemoglobin level change group.

To find out which intervention groups differed in meaning between the three groups, then post-tests 
were conducted with Tukey HSD. The results showed that the changes in the average $\mathrm{Hb}$ levels of papaya + Fe groups differed significantly from those of the Fe group, while the average change in the Papaya + Fe group with Vitamin C + Fe and the Vitamin C + Fe group with the Fe group did not differ in meaning (Table 6).

\section{Discussion}

Anemia in any form is harmful and the consequences discussed are applicable to all types of anemia [11]. Anemia is the most common morbidity among micronutrients and affects health, education, economy, and productivity of the entire nation [2]. Menstruating girls were at around double the risk of being anemia than non-menstruating girls [12]. One of the efforts in preventing and controlling anemia in adolescent girls is by giving Vitamin C samplings, consumption of papaya, and $\mathrm{Fe}$. The results of research in the midwifery group of the Department of Midwifery showed that there was an increase in hemoglobin levels in all groups. The increase in hemoglobin levels was relatively higher in the papaya $+\mathrm{Fe}$ group. The statistical results of the one-way ANOVA test showed that there were significant differences in changes in hemoglobin levels $(p>0.05)$. The consumption of papaya $+\mathrm{Fe}$ increases hemoglobin levels more than

Table 5: Average difference test results (one-way ANOVA test) in the changes in hemoglobin levels

\begin{tabular}{llll}
\hline Hemoglobin level & Mean \pm SD & Cl 95\% & p value \\
\hline Change & $1.37 \pm 1.21$ & $1.00-1.74$ & 0.03 \\
\hline
\end{tabular}

Vitamin C + Fe. The average difference of hemoglobin levels in each group due to the consumption of papaya containing Vitamin $\mathrm{C}$ together with $\mathrm{Fe}$ tablets was effective for increasing hemoglobin levels. Prevention of anemia naturally can be done by eating fruits that contain lots of Vitamin C such as papaya. Papaya also contains Vitamin $A$ and folic acid. Vitamin $A$ and folic acid help the formation of red blood cells, so they can interact with iron. Giving Vitamin C $100 \mathrm{~g}$ and Fe $60 \mathrm{mg} 9$ times in 3 weeks can increase hemoglobin levels. An intensive iron supplementation program and a combination of nutritional education/monthly counseling can reduce anemia [13]. The results of other studies show that the use of fortified foods is more effective in reducing anemia in developing countries compared to non-fortified food products [14].

Table 6: Average difference test results (Tukey HSD) in the changes in hemoglobin levels

\begin{tabular}{lllll}
\hline (I) Group & $(\mathrm{J})$ Group & $\Delta$ Mean $(\mathrm{I}-\mathrm{J})$ & $\mathrm{p}$ value & $\mathrm{Cl} 95 \%$ \\
\hline Tukey HSD & & & & \\
Papaya + FE & Vitamin C + Fe & 0.72 & 0.21 & $-0.29-1.73$ \\
& FE & 1.14 & 0.02 & $0.13-2.15$ \\
Vitamin C + FE & Papaya + Fe & 0.72 & 0.21 & $-1.73-0.29$ \\
& Fe & 42 & 0.58 & $0.59-1.43$ \\
FE & Papaya + Fe & -1.14 & 0.02 & $-2.15--0.13$ \\
& Vitamin C + Fe & -0.42 & 0.58 & $-1.43-0.59$ \\
\hline
\end{tabular}

Multi-nutrient powder (MNP) interventions are relatively effective in increasing hemoglobin levels [15]. Other studies in Indonesia showed that the combination of intensive educational interventions and MNP can increase hemoglobin levels [16]. The prevalence of iron deficiency anemia is higher in children from poor families [17]. The study results showed that maternal education and family income influenced anemia status [1]. Cross-sectoral collaboration between the health sector and the education sector in providing education and nutritional counseling based on age and menarche status can reduce anemia prevalence [18]. The two-pronged strategy of increasing iron intake (dietary diversification and use of iron-fortified iodized salt) can accelerate the reduction in anemia [19]. The high prevalence of anemia in the present study might be related to the lifestyle of female students as well as their dietary habits. It is recommended that female students never skip breakfast as it is essential for their cognitive functions and physical activities [20].

\section{Conclusion}

Anemia is a serious health issue among young girls in Polytechnic of Health-Ministry of Health, Aceh. The consumption of papaya $+\mathrm{Fe}$ is more effective in increasing hemoglobin levels in young women who suffer from anemia. Respondents are advised to consume $\mathrm{Fe}$ tablets together with fruits or vegetables that contain Vitamin $\mathrm{C}$ to prevent anemia. Crosssectoral collaboration between the health sector and the education sector in providing education and nutritional counseling based on age and menarche status can reduce anemia prevalence.

\section{References}

1. Getaneh Z, Enawgaw B, Engidaye G, Seyoum M, Berhane M, Abebe $Z$, et al. Prevalence of anemia and associated factors among school children in Gondar town public primary schools, northwest Ethiopia: A school-based cross-sectional study. PLoS One. 2017;12(12):e0190151. https://doi.org/10.1371/journal. pone.0190151

PMid:29284032

2. World Health Organization. The Global Prevalence of Anaemina in 2011. Geneva: World Health Organization; 2015.

3. Kementrian Kesehatan. Pedoman Gizi Seimbang. Jakarta: Direktorat Jenderal Bina Gizi dan KIA; 2013.

4. Sultan $\mathrm{AH}$. Anemia among female college students attending the University of Sharjah, UAE: Prevalence and classification. J Egypt Public Health Assoc. 2007;82(3-4):261-71. PMid:18410711

5. Jawarkar AK, Lokare PO, Kizhatil A, Jawarkar JA. Prevalence of anemia and effectiveness of iron supplementation in anemic 
adolescent school girls at Amravati City (Maharashtra). J Health Res Rev. 2015;2:7-10.

6. Stoltzfus RJ, Dreyfuss ML. Guidelines for The Use of Iron Supplements to Prevent and Treat Iron Deficiency Anemia. Washington, US: ILSI; 2004.

7. Brown JE. Nutrition through the Life Cycle. $4^{\text {th }}$ ed. Wadsworth: Cengage Learning; 2011.

8. Casey GJ, Jolley D, Phuc TQ, TT TT, Thh DH, Montresor A, Biggs BA. Long-term weekly iron-folic acid and de-worming is associated with stabilised haemoglobin and increasing iron stores in nonpregnant women in Vietnam. PLoS One. 201030;5(12):e15691. https://doi.org/10.1371/journal.pone.0015691

PMid:21209902.

9. Rati SA, Jawadagi S. Prevalence of anemia among adolescent girls studying in selected schools. Int J Sci Res. 2014;3(8):1237-42.

10. Eliagita. Effect of consuming papaya (Carica papaya Linn.) on the level of hemoglobin and hematocrit in pregnant women with anemia. Belitung Nurs J. 2017;3(2):120-5.

11. Kotecha PV. Nutritional anemia in young children with focus on Asia and India. Indian J Community Med. 2011;36(1):8-16. https://doi:10.4103/0970-0218.80786

PMid:21687374.

12. Abalkhail B, Shawky S. Prevalence of daily breakfast intake, iron deficiency anaemia and awareness of being anaemic among Saudi school students. Int J Food Sci Nutr. 2002;53(6):519-28. https://doi.org/10.1080/09637480220164370 PMid: 12590747

13. Vir SC, Singh N, Nigam AK, Jain R. Weekly iron and folic acid supplementation with counseling reduces anemia in adolescent girls: A large-scale effectiveness study in Uttar Pradesh, India. Food Nutr Bull. 2008;29(3):186-94. https://doi. org/10.1177/156482650802900304

PMid:18947031
14. Detzel P, Wieser S. Food fortification for addressing iron deficiency in Filipino children: Benefits and costeffectiveness. Ann Nutr Metab. 2015;66(Suppl 2):35-42. https:// doi:10.1159/000375144

15. Mahfuz M, Alam MA, Islam MM, Mondal D, Hossain MI, Ahmed AMS, et al. Effect of micronutrient powder supplementation for two and four months on hemoglobin level of children 6-23 months old in a slum in Dhaka: A community based observational study. BMC Nutr. 2016;2:21.

16. Inayati DA, Scherbaum V, Purwestri RC, Wirawan NN Suryantan J, Hartono $\mathrm{S}$, et al. Combined intensive nutrition education and micronutrient powder supplementation improved nutritional status of mildly wasted children on Nias Island, Indonesia. Asia Pac J Clin Nutr. 2012:21(3):361-73.

PMid:22705425

17. Ncogo P, Romay-Barja M, Benito A, Aparicio P, Nseng G, Berzosa P. Prevalence of anemia and associated factors in children living in urban and rural settings from Bata District, Equatorial Guinea. PLoS One. 2017;12(5):e0176613. https:// doi.org/10.1371/journal.pone. 0176613 PMid:28467452

18. Regasa RT, Haidar JA, Anemia and its determinant of in-school adolescent girls from rural Ethiopia: A school based crosssectional study. BMC Womens Health. 2019; 19(1):98. https:// doi.org/10.1186/s12905-019-0791-5 PMid:31315626.

19. Kalaivani $K$, Ramachandran $P$. Time trends in prevalence of anaemia in pregnancy. Indian J Med Res. 2018;147(3):268-77. https://dx.doi.org/10.4103\%2Fijmr.IJMR_1730_16 PMid:29923516.

20. Al Hassan NN. The prevalence of iron deficiency anemia in a Saudi University female students. J Microsc Ultrastruct. 2015;3(1):25-8. https://doi.org/10.1016/j.jmau.2014.11.003 PMid:30023178. 